\title{
Memorial
}

\section{NORMAN SHUMWAY}

\section{Noedir Stolf*}

In the morning of 10th February of this year Dr. Norman E. Shumway passed away, in his house in Palo Alto, California one day after his 83rd birthday, with complications of a malignant neoplasia.

This event led me to write this simple text, as a just tribute that all members of our society must surely consider he deserves, for the attention and kindness that he repeatedly showed.

Dr. Shumway, emeritus professor of the University of Stanford, was born in Kalamazoo, Michigan, and started his education in the University of Michigan in 1941, with the intention of studying Law. During this period he was recruited to the Army for the Second World War. In the army, a vocational test showed his aptitude for medicine or dentistry. He chose medicine and graduated in the University of Vanderbilt in 1949. His residence was completed in the University of Minnesota, where he obtained a $\mathrm{PhD}$ in cardiovascular surgery in 1956.

In 1958 he was admitted as surgical instructor in the University of Stanford, in San Francisco, California. Transference to the Palo Alto campus enabled the Cardiovascular Surgery Service to be expanded. Shumway initiated in 1959, with the collaboration of, at that time resident, Richard Lower, research on transplantation in dogs, which constituted the greatest contribution of his group to cardiovascular surgery. Utilizing immunosuppression they standardized and improved the technique, reaching the first long-term survivals in this type of experimental transplantation. In his manner of speaking, he told me directly: "We started out doing this as a technical exercise and the animals began to survive". Although he affirmed that he was sure of the viability of human transplantation, the international community was taken by surprise by the first transplantation between humans performed by Dr. C. Barnard, in South Africa, on 3rd December 1967. Following, the first transplantation in the United States, performed by Dr. Kantrowitz in a child, Dr Shumway performed the second transplantation with the patient surviving a little more than two weeks. Many Services performed transplantations in this historical period, including Brazil under the leadership of Prof. E. J Zerbini. However, starting in 1970 there was an era of the disenchantment with the procedure. Only the

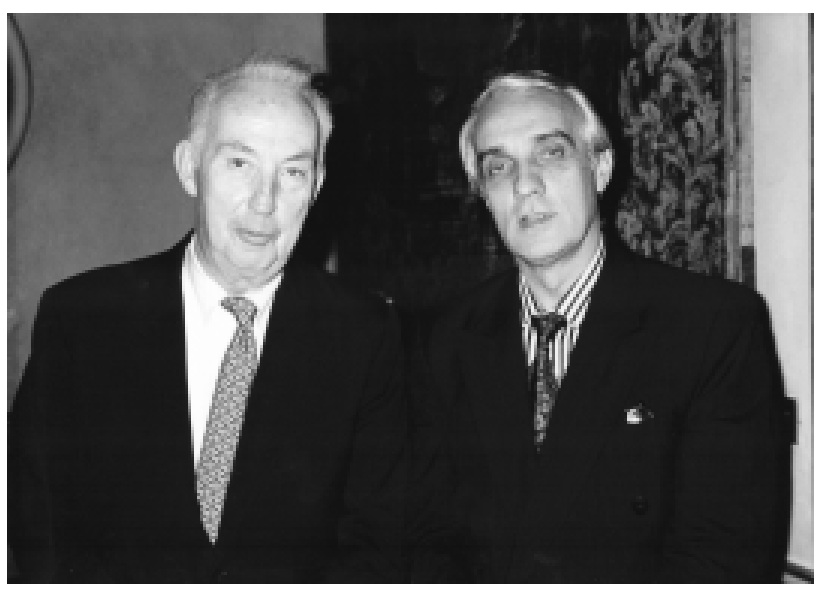

Dr. Norman Shumway and Dr. Noedir Stolf

groups of Stanford, South Africa, Richmond (led by Dr. Lower, egress of Stanford) and Pitié Salpêtrière Hospital in France remained enthusiastic and continued the research. Without doubts, without the contributions of Dr. Shumway's work the history of heart transplantation would not be the same or, at least, the procedure would have been significantly delayed.

As they maintained a continuous program of transplantation they accumulated precious experience in the control of donors and recipients, making endomyocardial biopsy safe, improving the Sakakibara technique (SchultzCaves); standardizing the important immunological monitoring methods in the pre-cyclosporine era; they implanted the process of distance organs procurement and finally introduced cyclosporine in Heart Transplantation (after kidney transplantation that started in 1978). These contributions gave an improvement in the results and in the 1980s heart transplantation became more accepted.

The Cardiovascular Surgery Department of Stanford continuously maintained transplantation projects in dogs, always performed by the chief resident of the Service. It did not stop there; a project of heart-lung transplantation in monkeys was initiated with the chief resident, Bruce Reitz.

In 1981, Shumway and Reitz performed for the first time in humans this double transplantation. The patient lived for five years.

Everyone knows that the University of Stanford Service produced many other important contributions in the field of cardiovascular surgery, such as: 1 - myocardial protection (topical hypothermia), 2 - valve replacement and 3 - 
dissections and aortic aneurysms. Dr. Shumway received the most important honors of American Medical Societies, not only from his specialty, but from many others.

Independently of the role Dr. Shumway performed in the development of this work in the University of Stanford and in cardiovascular surgery, he was considered an unrivaled figure. His social life was always simple, he was receptive and friendly. With fine irony he always demonstrated a sagacious and non-aggressive humor. In the professional and scientific field, he also had direct and simple ideas.
Dr. Norman E. Shumway was professor and head of the Thoracic and Cardiovascular Surgery Department of the University of Stanford up his retirement in 1993.

He left a wife (his first and only), four children, one of whom (Sara) is a cardiovascular surgeon, and two grandsons. But most of all, those who knew him miss him.

*Associate professor of the Thoracic and Cardiovascular Surgery Section of the Medical School of USP, Head of Service of UDT-Stolf and member of SBCCV 